\section{ABSORPTION OF WATER BY THE LEAVES OF PLANTS}

THE experiments of Boussingault, referred to in NATURE, vol. xviii. p. 672, find a fitting sequel in those of the Rev. G. Henslow, detailed in a paper read before the Linnean Society on Norember 7. Although gardeners universally maintain that growing plants have the power of absorbing water through their leaves, both in the liquid and the gaseous form, in addition to the power of suction through the roots, yet the contrary theory has been in favour during recent years among vegetable physiologists. The first recorded experiments of any value on the subject were about the year 1727 , by Hales, ${ }^{1}$ as described in his "Statical Essays;" the conchusion to which he came being that "it is very probable that rain and dew are imbibed by vegetables, especially in dry seasons." This result was confirmed by Bonnet in 1753. A century later, however, in 1857 , Duchartre, experimenting on the absorptive power of plants, came, after considerable wavering, to the conclusion that rain and dew are not absorbed by the leaves of plants. This opinion has been, with but little exception, held by all physiologists during the last twenty years, notably by De Candolle and Sachs; the explanation offered of the fact that withered plants revive when placed in moist air or when the leaves are moistened, being that transpiration is thus stopped, or is more than counterbalanced by the root-absorption. In his "Text-book of Botany" (English edition, p. 613), Sachs says:- "When land-plants wither on a hot day, and revive again in the evening, this is the result of diminished transpiration with the decrease of temperature and increase of the moisture in the air in the evening, the activity of the roots continuing; not of any absorption of aqueous vapour or dew throngh the leaves. Rain arain revives withered plants, not by penetrating the leaves, but by moi-tening them, and thus hindering further transpiration, and conveying water to the roots, which they then conduct to the leaves. McNab has, however, proved that leaves to transpire, even in a moist atmosphere, provided they are exposed to the action of light.

The results of Mr. Henslow's experiments, extending over several years, are altogether in accordance with those of boussin. gault, and may be considered to set the question of the absorbent power of the leaves of plants completely at rest. The following are the chief conclusions arrived at:- $-\mathbf{r}$. The absorption of water by internodes. The experiment consisted of wrapping up one or more internodes of herbaceous plants in saturated b) lotting-paper and in noticing the effects. As a rule the leaves on the shoots rapidly perished, showing that transpiration was too great for the supply. The stems, however, kept fresh for different periods up to six weeks. 2. Absorption by leaves, to see how far they could balance transpiration in others on the saine shoot. The general result is that as long as the leaves remain green and fresh in or on water, they act as absorbents, but that the leaves in air keep fresh or wither according as the supply equals or falls short of the demand. 3. To test how far leaves on a shoot can nourish lower ones on the same shoot. It appears that it is quite immaterial to plants whether they be supplied from witter by the absorbing leaves being above or below those tratspiring. Water flows in either direction equally well. 4 Leares floating on water. It was found that one part of a leaf cnn nourish another part for various periods, though the edges out of water died first. 5. Absorption of dew. A long series of cut leaves and shoots were gathered at 4 P.M., then exposed to sun and wind for three hours, then carefully weighed and exposed all night to dew. At 7.30 A.M., after having been dried, they rere weighed again, and all had gained weight and quite recovered their freshness, proving that slightly wetted detached portions do absorb dew. 6. Imitation dew. Like results followed from using the "spray," by which dew could be exactly imitated. 7 . Plants growing in pots and of which the earth was not watered, were kept alive by the ends of 'one or more shoots being placed in water; e.g., Minnulus moschatus not only grew vigorously and developed axillary buds into shoots, but even blossomed.

By these interesting experiments the physiological botanist is again placed in harmony with the gardener who syringes his plants, not merely for the purpose of washing off dust and insects, but in order to facilitate the actual absorption of water by the surface; and with the field botanist, who sprinkles the plants in his vasculum with water to keep them fresh till he

In his " Geschichte der Botanik," pp. 5x5-521, Sachs gives an admirable epitmme of the great service rendered to the progress of botanical science by the researches of this eminent botanist and physicist. reaches hone. The fact which now seems established begond all doubt by the observations of Darwin and others, that certain plants have the power of absorbing through their leaves and digesting the remains of animal substances, also implies, as a necessary corollary, the absorbent power of leaves for certain liquid or gaseous substances. In connection with this subject sufficient attention has perhaps not been attracted to the observations of Prof. Calderon, as detailed in a paper printed at Madrid, in English ( I877), entitled, "Considerations on Vegetable Nutrition." Calderon's statements-which, however, require at present to be confirmed by other observers-are to the effect that plants have the power of absorbing the nitrogenous oryanic matter which is constantly floating in the air, and that, if air be deprived of all organic matter, it is unable to sustain vegetable life, all the physiological functions of plants being then suspended.

A. W. B.

\section{UNDERTONES}

THESE formed the subject of a lecture delivered by $\mathrm{Her}^{\mathrm{r}}$ Auerbach before the meeting of Naturalists at Casse this year.

The term "undertones," he pointed out, is an extension of the nomenclature which denotes certain accompanying tones of a given note "overtones." Undertones may be observed in the following way:-If a struck tuning-fork be set on a soundboard, a tone is heard sounding strongly, which before was little perceptible. The stem of the fork makes longitudinal vibrations, which, by action on the sounding-board (a very thin one), generate transverse vibrations, and these spread over the large surface of the plate: Should the tone of the board only differ in intensity from that of the fork, the vibrations executed by the stem of the tuning-fork must be small; it is otherwise, however, when the vibrations exceed a certain amount.

Herr Auerbach demonstrated his observation with a tuningfork giving the $\mathrm{A}$ of a violin, and so 435 vibrations per second. When he placed the vibrating fork firmly on a sonud-board, the tone was heard distinctly at a distance. When, however, he brought the tuning-fork, struck very vigorously, into very light contact with the plate, there was heard the lower octave of the fork's tone. With other materials, which were not then at his command, he could produce also the lower fifth of the lower octave, and the lower fourth of this tone, i.e., the double octave of the fork's tone. The vibration numbers of these resonance tones are $\frac{1}{2}, \frac{1}{3}, \frac{2}{4}, \&$ c., of that of the tuning-fork's tone, i.e., the resonance-tones form the series of the harmonic zundertones.

With regard to the mode of occurrence of these tones, Her: Auerbach said this: "To prove to you, first of all, that the strength of the vibrations is the fundauiental condition of the phenomenon, I will once more make the experiment, and continue it longer. You heard first, again, the lower octave; but then the tone sprang over into the higher, so that it became identical with the proper tone of the tuning-fork. Consider this result along with the fact that the vibrations of the fork rapidly diminish; remember, too, that it is only when the fork is vigorously struck and lightly placed on the plate that the undertones occur, and you will see that the cause of the phenomenon lies in the amplitude of the vibrations."

Herr Auerbach further supposes that the resonance-surface of the plate, being imperfectly elastic, follows the movements of the stem of the fork immediately downwards indeed, but not up. wards; an interval then occurs which only disappears on the next passage downwards of the stem. If the retardation be a smail one, the plate, at the moment of meeting the stem a second time, has nearly completed a vibration. If, however, the retardation be great, the undertones arise (as the lecturer showed graphically) from the combination of the vibrations of the stem and the plate. The stem-end, i.e., in this latter case, is no longer an unconditionally free end, but its freedom is a periodic function of the time, and this period is twice as great as that of the tuning-fork vibrations. "That the undertones arise in consequence of internal friction, was easy to see a priori: what the experiments have shown and explained is the interesting fact, that precisely the harmonic undertones are produced; that is a consequence of the fact that the resonance is the action of a periodic force, and so, in a certain sense, a discontinuous phenomenon, otherwise the undertones must form a continuous series, which is not the case."

See Niture, vol. xv. p. 108. 